\title{
Perspectivas feministas africanas e orga- nizações de mulheres em Moçambique
}

\author{
Paz na Terra, Guerra em Casa: \\ feminismos e organizações de \\ mulheres em Moçambique.
}

\section{CASIMIRO, Isabel Maria.}

Série Brasil \& África-Coleção Pesquisas 1, Pernambuco: Editora da UFPE: 2014, $376 \mathrm{p}$.

O livro da socióloga moçambicana Isabel Maria Casimiro é resultado da sua tese de mestrado' em Sociologia, defendida em Coimbra, Portugal, em 1999. Foi publicado no Brasil, em 2014, pela Universidade Federal de Pernambuco (UFPE) ${ }^{2}$. A publicação é ilustrativa de sua trajetória acadêmica, profissional e militante ${ }^{3}$, aspectos imbricados com sua vida pessoal e na realização da pesquisa, representando o que ela denomina como "espelho de sua vida" (Isabel Maria CASIMIRO, 2014). É pesquisadora do Centro de Estudos Africano (CEA), da Universidade Eduardo Mondlane (UEM), em Moçambique ${ }^{4}$, onde atua no Departamento de Estudos da Mulher e Gênero (DEM) e no Núcleo de Estudos da Mulher (NEM). Foi fundadora da organização não governamental regional (ONG) Women and Law in Southern Africa Research and Education Trust (WLSA), além da Associação Mulher, Lei e Desenvolvimento (MULEIDE) ${ }^{5}$ e do Fórum Mulher.

No livro Paz na Terra e Guerra em Casa Casimiro (2014) analisa o início do movimento pela emancipação e cidadania das mulheres em Moçambique no período de luta anticolonial e após a independência em relação ao colonialismo português, demonstrando a dificuldade dos políticos nacionalistas para a aceitação das mulheres nas frentes de lutas. $O$ trabalho se utiliza de uma perspectiva feminista crítica, com aspectos do feminismo marxista, nacionalista e pós-estruturalista.

A obra está organizada em seis capítulos. O primeiro, analisa o feminismo e as teorias feministas, criticando a cultura patriarcal ocidental e a produção de relações humanas baseadas na submissão ao poder da razão, que produz conflitos e clivagens, levando a uma crise civilizatória sem precedentes.

Verifica que a sociedade civil se rearticulou na África, na Ásia, no Leste Europeu e na América Latina nas lutas contra as ditaduras e pela (re)democratização, levando ao surgimento dos novos movimentos sociais, desafiados a enfrentar o que Casimiro (2014, p. 75-76) chama de "o desencanto do mundo". Neste capítulo Casimiro trata das "vagas do feminismo" articulada com a realidade da África, onde os movimentos de mulheres e feminismos emergem das seguintes frentes: 1) o movimento endógeno de mulheres nas sociedades africanas; 2) a resistência anticolonial; 3) os movimentos de libertação nacional; e 4) os grupos de mulheres profissionais e acadêmicas, com independência econômica.

Esses movimentos questionaram os paradigmas de desenvolvimento conservadores e conformistas, confrontando-os com o resgate da história das mulheres sem cair nos erros da corrente central da historiografia africana, que desconsidera as especificidades das experiências e as diversidades das mulheres desses países (CASIMIRO, 2014).

No capítulo seguinte, analisa as relações entre o Estado, a sociedade e a situação das mulheres em África. Casimiro (2014) verifica que, 
após as independências, os países africanos passaram a ser dirigidos pela pequena-burguesia e se caracterizaram pela crise de acumulação, pela ditadura de partido único e pela ausência de democracia social. A autora demonstra como os movimentos buscaram alternativas fora do receituário tradicional:

[...] as mulheres têm sido exímias na sua capacidade de 'costurar' diferentes estratégias de resistência, em espaços para si desconhecidos, mas em que elas penetram através duma construção diferente de espaço, através de uma diferente linguagem, maneira de vestir, de cuidar da sua família, através de redes que vão engendrando, e em que se verifica uma miscigenação de culturas (CASIMIRO, 2014, p. 146).

Casimiro enfatiza a importância do protagonismo das mulheres na história de África para a construção de sua autonomia econômica, contribuindo para a visibilidade e emergência das vozes das mulheres, assim como questiona os estudos que representam a mulher africana como vítima e de uma autenticidade estática pobre e rural (MCFADDEN, 1998 apud CASIMIRO, 2014). Critica os estudos que naturalizam as mulheres africanas como conservadoras e reprodutoras das culturas que refletem o atraso, o exotismo e o erotismo dos seus corpos.

A autora, no terceiro capítulo, adota uma perspectiva histórica, articulando aspectos sociais, políticos, econômicos, culturais, ideológicos e psicológicos, focalizando as dimensões objetivas e subjetivas das mulheres moçambicanas e suas organizações. Sintetiza o período colonial, a organização da resistência armada, a ação da Frente de Libertação de Moçambique (FRELIMO), o período pósindependência e a atualidade (CASIMIRO, 2014).

As mulheres moçambicanas adquiriram um protagonismo como sujeito histórico através do movimento nacionalista, em 1962, com a criação da FRELIMO. A participação na luta armada levou-as a questionarem seu papel, as relações sociais de gênero e o projeto de sociedade a ser construído. Na visão de Casimiro, o processo revolucionário oportunizou políticas de participação, favorecendo a eleição de muitas mulheres para cargos públicos. Entretanto o aparelho de Estado teria cooptado os quadros da FRELIMO, que não transformaram as estruturas herdadas do sistema colonial, mantendo práticas autoritárias e um modelo de desenvolvimento que logo caminhou para a estagnação econômica e tampouco questionou as contradições na vida privada:
[...] não se verificou um repensar das tarefas reprodutivas da mulher, ou seja, das tarefas invisíveis que já se ocupavam bastante, e que contribuíram para aumentar seu tempo de trabalho, no âmbito da divisão sexual do trabalho (CASIMIRO, 2014, p. 190).

A Organização da Mulher Moçambicana (OMM) e a União Geral das Cooperativas (UGC) são apresentadas no quarto capítulo e situadas no contexto das políticas de ajuste estrutural, no desmantelamento do Estado de bem-estar social e na fundação das Organizações Não Governamentais (ONGs), difundidas a partir da ascensão do neoliberalismo e do desvio do papel do Estado redistributivo.

Na década de 1990 surgem organizações da sociedade civil, capazes de contribuir com a governança, realizando pressões e controle sobre as instituições do Estado. Entre elas estão as organizações de mulheres de caráter voluntário, sem fins lucrativos, baseadas em solidariedades "tradicionais" do período pré-colonial, reproduzidas no período pós-independência. Casimiro avalia que essas formas de entreajuda e solidariedade resistiram ao período colonial e hoje são importantes estratégias de sobrevivência no âmbito rural e urbano, originando cooperativas independentes, como a UGC, fundada em 1980 A OMM, braço feminino da FRELIMO, foi criada em 1973 e sua organização nacional, com capacidade de mobilização das mulheres integrou-as nas tarefas de reconstrução do país no período pós-colonial.

No quinto capítulo Casimiro analisa as organizações de mulheres entre 1987-1997, concentrando a pesquisa no Gabinete da Esposa do Presidente da República (GEPR) e nas organizações Associação Mulher, Lei e desenvolvimento (MULEIDE), Fórum Mulher e Associação Moçambicana Mulher e Educação (AMME). O GEPR foi criando em 1990, de responsabilidade da Primeira-Dama, orientado por uma perspectiva assistencialista, se caracteriza como a femocrata, pelo fato de suas dirigentes serem ligadas às elites no poder. Conforme a pesquisadora, a "femocracia é uma estrutura de poder feminino antidemocrático, que se proclama em defesa da mulher comum, mas que não a realiza na prática, por estar dominada por uma pequena elite de mulheres [...]" (CASIMIRO, 2014, p. 206).

A MULEIDE, criada em 1990, é uma rede regional africana, existente em 15 países, e se dedica à defesa dos direitos das mulheres, envolvendo organização e pesquisa de setores do movimento de mulheres, governos e ONGs. 
Segundo Casimiro, seus objetivos são a troca de experiências nas áreas de educação, a reforma política e serviços jurídicos, a promoção de direitos civis, a investigação de problemas legais e a implantação de uma rede de emergência às violações das mulheres.

Já em Moçambique foi criado em 1994 o Fórum Mulher (Coordenação para a Mulher e Desenvolvimento), que articula um conjunto de 84 organizações de variada natureza (mulheres, homens, organizações nacionais e internacionais, agências das Nações Unidas, organizações governamentais e não-governamentais, organizações religiosas, ligas de partidos políticos, organizações camponesas, operárias, empresários, cooperativas e sindicatos). Seu objetivo é lutar pela liberdade e igualdade das mulheres. Nesse mesmo ano foi criada a Associação Moçambicana Mulher e Educação (AMME) com o objetivo de valorizar e elevar as condições socioeconômicas da mulher docente moçambicana do ensino primário, sendo, para Casimiro, um exem plo do protagonismo das mulheres, transformando sua situação de vítimas em lutadoras.

O livro de Casimiro oferece um guia para percorrer um referencial teórico de pesquisadoras/es africanas/es (especialmente teóricas feministas), possibilitando o acesso a uma literatura pouco comum na América Latina. Suas referências interdisciplinares se estendem em diálogo com africanistas feministas e com o pensamento pós-colonial. Sua pesquisa se fundamenta, portanto, numa diversidade de paradigmas para pensar os feminismos do Sul, evidenciando um consistente trabalho de valorização do saber das mulheres e dos estudos de feministas africanos na busca do diálogo com feministas latino-americanas.

Em seu trabalho Casimiro dialoga com If Amadiume (1997) e ressalta que as mulheres africanas trouxeram duas contribuições únicas e específicas para a história mundial e para a civilização:

A primeira é o matriarcado como uma base social e ideológica fundamental na qual assentavam o parentesco africano e os sistemas sociais e morais mais vastos. O segundo directamente relacionado com este factor matriarcal, que é o carácter dual-sex (sexodual) dos sistemas políticos africanos, uma característica unicamente africana (AMADIUME, 1997 apud CASIMIRO, 2014, p. 76-77).

Casimiro contribui para os estudos feministas e de gênero ao refletir sobre as dimensões de um sistema matriarcal de tradição africana, que agrega o social, o econômico e o político, dominado pelas mulheres que estavam no controle da agricultura, do mercado, do comércio e da religião. Ele coexistia com um sistema patriarcal (dominado pelos homens), em cooperação e partilha do espaço social:

O matriarcado não era equivalente ao patriarcado porque não estava baseado na apropriação e na violência. A base fundamental do matriarcado era o agregado familiar e não a família - como nas sociedades Europeias, já patriarcais quando da invasão dos povos IndoEuropeus - o que fez com que as mulheres [...] tivessem tido uma proeminência nas estruturas sociais Africanas [...] (AMADIUME, 1997 apud CASIMIRO, 2014, p. 78).

Outra contribuição importante dessa pesquisa é a abordagem crítica a determinadas teorias feministas que interpretam de forma essencialista as mulheres africanas, especialmente no que diz respeito à subordinação e à falta de agência. Segundo Casimiro, ainda que no continente o patriarcado e o colonialismo sejam predominantes, as mulheres resistem e se reinventam a partir de suas necessidades de sobrevivência, criando o que ela chama de "feminismo popular". De acordo com a autora, são as "mulheres do povo" que necessitam de respostas imediatas às necessidades objetivas de sobrevivência e que incorporam reivindicações de gênero, ainda que sem consciência da luta feminista (CASIMIRO, 2014, p. 269).

\section{Notas}

' Naquele país, diferente do Brasil, utiliza-se a denominação tese para se referir à dissertação.

${ }^{2}$ A Série Brasil \& África, segundo o editor Marco Mondaini, dialoga com "a virada geopolítica ocorrida no Brasil no início do século XXI, que aponta para a mudança na ordem de prioridades no campo das relações internacionais, com a passagem de ênfase do diálogo 'NorteSul' para o diálogo 'Sul-Sul'” (CASIMIRO, 2014, p. 11).

${ }^{3}$ Foi integrante do movimento FRELIMO (Frente de Libertação de Moçambique), além de exercer mandato parlamentar de Deputada, como representante do Partido Frelimo (Frente de Libertação de Moçambique).

${ }^{4}$ Moçambique é um país localizado no sudeste do Continente Africano.

${ }^{5}$ MULEIDE Associação Mulher, Lei e Desenvolvimento. Disponível em: http://www.muleide.org.mz/index.php/amuleide. Acesso em: 10/01/2016.

${ }^{\circ} \mathrm{O}$ que equivale nos estudos feministas do Ocidente às "ondas do feminismo".

\section{Referências}

AMADIUME, Ifi. Reinventing Africa. Matriarchy, Religion, Culture. London \& New York: Zed Books Ltd, 1997. 
CASIMIRO, Isabel Maria. Paz na Terra, Guerra em Casa. Série Brasil \& África-Coleção Pesquisas 1, Pernambuco: Editora da UFPE: 2014.

FORUM MULHER. Disponível em: http://ibismozambi que.org/parceiros/forum-mulher/. Acesso em: 10/ 01/2016.

MCFADDEN, Patricia. Feminist Thinking and African Women's Perspectives. SAPEM, Vol. 11, Número 4, Harare, 1998.

MULEIDE. Associação Mulher, Lei, Desenvolvimento. Disponível em: http://www.muleide.org.mz/ index.php/a-muleide. Acesso em: 10/01/ 2016.

[Recebida em 19/08/2016 e aceita para publicação em 31/08/2016]

Vera Fátima Gasparetto Universidade Federal de Santa Catarina, Florianópolis, Santa Catarina, Brasil

Vera Fátima Gasparetto (gasparettovera@yahoo.com.br). É doutoranda no Programa de Pós-Graduação Interdisciplinar em Ciências Humanas (PPGICH), da Universidade Federal de Santa Catarina, orientada pela Profa. Dra. Luzinete Simões Minella. Mestra em Sociologia Política (UFSC, 2014), possui Graduação em Comunicação Social Jornalismo (Universidade do Vale do Rio dos Sinos, 1996). É educadora na Escola Sindical Sul da CUT. Atua nas áreas de desenvolvimento e políticas públicas, comunicação, imagem da mulher na mídia, educação para a comunicação, mundo do Trabalho, juventude e gênero. 